\title{
The growth-maintaining activity of ascorbic acid
}

\author{
By J. R. EVANS AND R. E. HUGHES \\ Welsh College of Advanced Technology, Cardiff \\ (Received 6 September 1962-Revised 26 November 1962)
}

It is frequently assumed that the growth-maintaining action of essential nutritional factors results from their specific participation in the processes affecting tissue formation. It has been shown, however, that sometimes animals receiving a nutritionally incomplete diet have a reduced food intake when compared with animals receiving the complete diet, and the suggestion has been made that this reduced food intake is at least in part responsible for the impaired growth of the deficient animals. It has been known since the studies of Osborne \& Mendel (I9I8) that animals may eat sparingly of diets deficient in certain essential factors. Similar evidence has been provided for children receiving diets deficient in lysine (Albanese, 1959). Stewart (1953) attributed the defective growth of cobalt-deficient lambs to their demonstrably lowered food intakes. More recently, Beaton, Hellebust, Paul \& Wright (I960) obtained results that led them to conclude that the primary action of vitamin $\mathrm{C}$ on the growth of guineapigs is one mediated by food intake. Of interest also is the finding of Hugot \& Causerot (1957) that vitamin D has no apparent effect on the growth of rats whose food intake is restricted.

As a preliminary to experiments on the metabolic role of ascorbic acid in tissue formation in guinea-pigs, it was considered of value to assess the relative importance of these two possible actions of the vitamin, i.e. to determine whether the growthmaintaining activity is primarily on tissue formation per se or primarily on appetite and food intake.

Two experiments were done.

\section{EXPERIMENTAL}

Expt I. The mean rate of increase in weight of eight male guinea-pigs (group A) receiving suboptimal amounts of ascorbic acid was compared with that of pair-fed animals (group B) receiving optimal quantities of the vitamin.

Expt 2. The mean daily food intake of eight male guinea-pigs (group C) receiving optimal amounts of ascorbic acid and having unrestricted food was compared with that of eight similar animals (group D) also having unrestricted food but receiving suboptimal amounts of ascorbic acid.

Animals. White male guinea-pigs of approximate initial weight $260 \mathrm{~g}$ were used. They were housed in individual galvanized zinc cages, with removable $\frac{7}{16}$ in. mesh bottoms.

Diet. The pelleted diet Oxoid $4 \mathrm{I}$ B (Modified) (Oxo Ltd, London) was used in both experiments. The manufacturer's data indicate that the components of the diet are Sussex-ground oats $40 \%$, wholemeal flour $46 \%$, white-fish meal $8 \%$, dried 
skim-milk $3 \%$, and dried yeast $\mathrm{I} \%$, together with all necessary minerals and vitamins, but no vitamin C. Previous work by us (I96I, unpublished) had shown this to be a satisfactory scorbutogenic diet for guinea-pigs; it supported normal growth if supplemented with ascorbic acid. Animals receiving suboptimal amounts of the vitamin were dosed orally with $0.4 \mathrm{mg}$ ascorbic acid in I ml water daily; animals receiving optimal doses were given $8 \mathrm{mg}$ in $\mathrm{I} \mathrm{ml}$ water daily. Food intakes were measured by offering each animal $5^{\circ} \mathrm{g}$ of the diet each day and weighing the amount uneaten $24 \mathrm{~h}$ later. Before calculation of food intake, food spilled from the pot was collected on squares of filter-paper placed in the cage tray and added to the residue remaining in the pot. In Expt $\mathrm{I}$ the animals in the pair-fed group received on any particular day the amount of food eaten by their controls on the day before. All animals received water ad lib. The animals received the diet without ascorbic acid supplements for I week before being divided into the experimental groups; this was done to ensure low tissue levels of ascorbic acid at the beginning of the experiment.

Measurement of tissue ascorbic acid. The animals were beheaded when the experiments had continued for 8 weeks. The ascorbic acid content of the adrenal glands was determined by the method of Bessey (1938) with the slight modifications described by Hughes (1956). The concentration of ascorbic acid in the gland was taken as an index of the ascorbic acid status of the animal.

\section{RESULTS}

The changes in mean body-weights of the animals in the two groups in Expt I are given in Fig. I; the results are summarized in Table I. The results of Expt 2 are given in Fig. 2, the two upper graphs recording the changes in body-weight in the two groups and the lower ones the mean food intake per animal over the same period.

Table I. Summary of results of Expt I

(Mean values with standard deviations)

$\begin{array}{lcc} & \text { Group A } & \text { Group B } \\ \text { No. of guinea-pigs } & 8 & 8 \\ \text { Ascorbic acid supplement }(\mathrm{mg} / \mathrm{day}) & 0.4 & 8 \\ \text { Adrenal ascorbic acid* }(\mathrm{mg} / \mathrm{IO0} \mathrm{g}) & 10 \cdot 0 \pm 3 \cdot 1 & 62 \cdot 7 \pm 18 \cdot 9 \\ \text { Initial body-weight }(\mathrm{g}) & 279 \pm \mathrm{I} 5 & 278 \pm 15 \\ \text { Final body-weight }(\mathrm{g}) * & 32 \mathrm{I} \pm 52 & 452 \pm 49 \\ \quad \text { Difference between the two groups significant }(P<0.01) .\end{array}$

Expt $\mathrm{I}$ indicated that, under the experimental conditions described, ascorbic acid has an effect upon the guinea-pig's ability to use ingested food for the purposes of growth. This effect is clearly seen by comparing the mean growth rates and final body-weights of groups A and B (Fig. I, Table I). Group A (ascorbic acid intake of $0.4 \mathrm{mg}$ daily) made poor use of the food consumed; group B (ascorbic acid intake of $8 \mathrm{mg}$ daily) had a much greater rate of increase in body-weight, although the food intake was the same as that of group A. Both groups had similar mean initial bodyweights ( $278 \mathrm{~g}$ and $279 \mathrm{~g}$ respectively); at the end of the experiment the mean weight 
of the animals in group B was $452 \mathrm{~g}$ compared with a mean final weight of $32 \mathrm{I}$ for the animals of group $\mathrm{A}$, the difference being highly significant $(P<0.01)$. The different concentrations of ascorbic acid in the adrenal glands of the animals from these groups indicated that the different intake levels of the vitamin were validly reflected in the gland. The experiment suggests that ascorbic acid has a specific metabolic effect resulting in an increase in body-weight, though it does not permit us to discount the possibility of an appetite effect also.

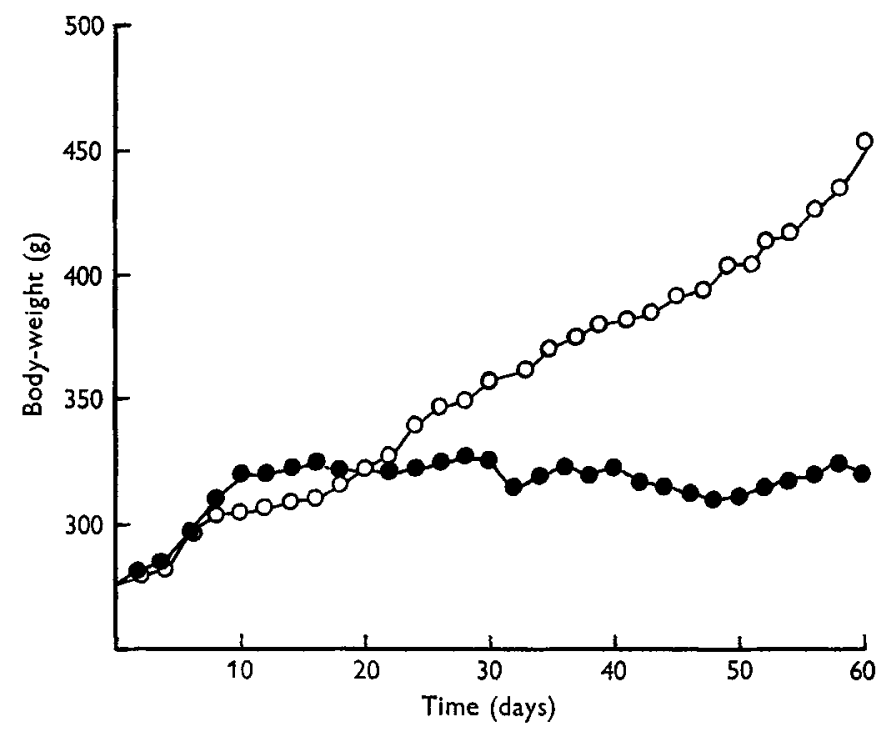

Fig. 1. Expt I. Changes in mean body-weight of guinea-pigs in group A (-) receiving $0.4 \mathrm{mg}$ ascorbic acid daily and in group $\mathrm{B}(\mathrm{O}-0)$ pair-fed with group A and receiving $8 \mathrm{mg}$ ascorbic acid daily.

Expt 2 gives information about the effect of ascorbic acid on food intake. It will be seen from Fig. 2 that the food consumption of the animals of group D (low ascorbic acid intake) showed no reduction when compared with the food consumption of group $\mathrm{C}$ (high ascorbic acid intake). During the final stages of the experiment the food consumption of group $\mathrm{C}$ was the higher of the two, but this was presumably a result of the much greater weight of the animals in group $C$ than of those in group $D$ during the latter phase of the experiment. Indeed, expressed on a body-weight basis, the food intakes of group D were consistently higher than those of group C.

\section{DISCUSSION}

In both experiments the aim was to produce a condition of chronic scurvy over a period of weeks rather than acute scurvy ending in the death after 3-4 weeks of the animal completely deprived of ascorbic acid, which would have shortened the time available for comparison of effects. Also, the behaviour of animals dying from scurvy is highly abnormal during the week before death, and it is difficult in such animals to distinguish between effects that may validly be attributed to avitaminosis $\mathrm{C}$ and such 
secondary effects as those resulting from inanition, general weakness and tissue breakdown. In chronic scurvy, however, it may fairly be assumed that any differences between the test animals and the control ones are a result of the different levels of ascorbic acid intake.
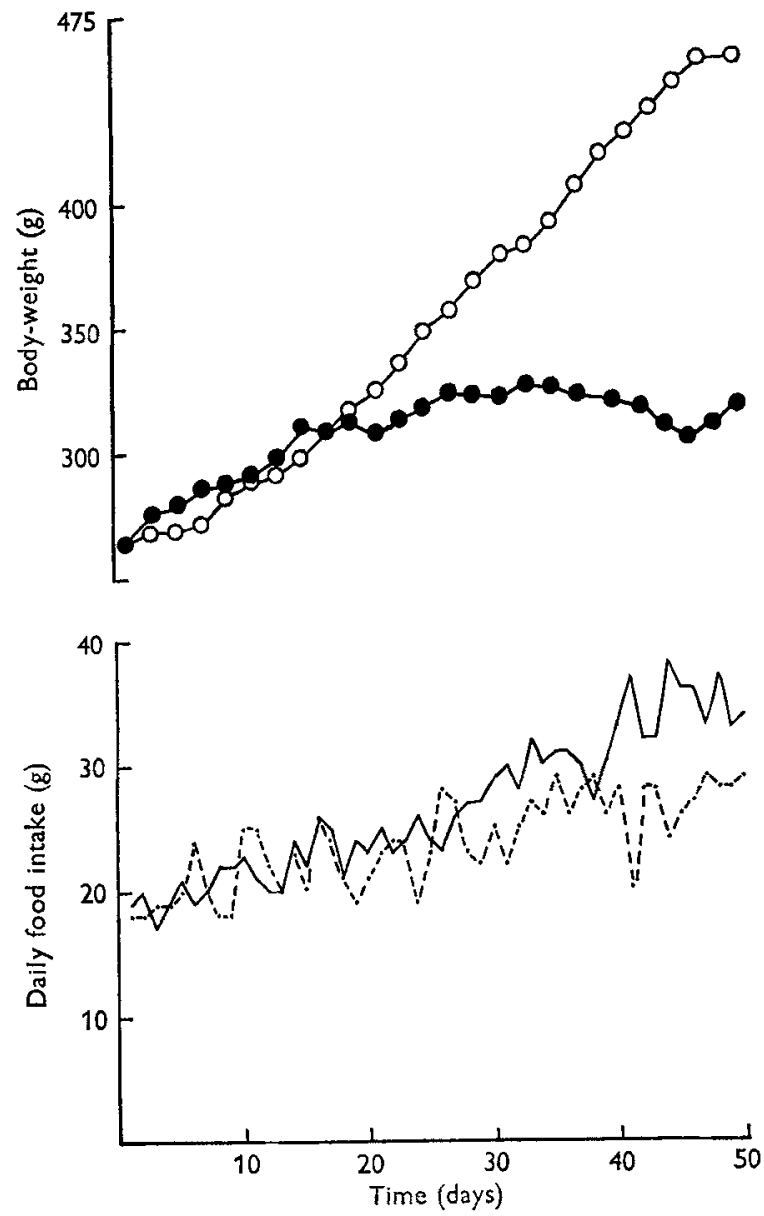

Fig. 2. Expt 2. Mean daily intake of food (lower graphs) and mean body-weight for the same period (upper graphs) of guinea-pigs in groups $\mathrm{C}(-$, food intake; $0-0$ bodyweight) and D (-- , food intake; $-\bullet$, body-weight) receiving $8 \mathrm{mg}$ and $0.4 \mathrm{mg}$ ascorbic acid daily respectively.

The results suggest that the growth-maintaining action of ascorbic acid is a specific effect related in some way to the processes involved in tissue formation; the poor growth with a diet low in ascorbic acid cannot be attributed to a reduced food intake. It is difficult to reconcile these results with those of Beaton et al. (I960) or to give unqualified acceptance to their conclusion ' ... the effect of ascorbic acid on body-weight is largely one of food intake rather than of a specific effect on the growth processes'. These workers too compared normal animals with pair-fed chronically scorbutic ones, but they were unable to demonstrate any marked difference between the increases in 
body-weight of the two groups. It may be noted that they used the semi-synthetic diet of Reid \& Briggs (1953), and it is of interest in passing to note that Fidanza \& Constable (I960), also using the Reid \& Briggs diet, report results suggesting that in rats the growth-maintaining effect of pantothenic acid is apparently mainly an appetite effect. It is indeed possible that changes in food intake in response to different dietary levels of essential nutrients are closely related to factors such as general acceptability of the diet. Possibly the acceptability of the semi-synthetic powdered diet of Reid \& Briggs is lower than that of the pellet diet used by us. There may be a delicate balance between acceptability, level of essential nutrients and food intake. Whatever the explanation of these apparent differences, in our own experiments with a compounded pellet diet the findings point to ascorbic acid having a clear metabolic or growth effect rather than an action mediated through food intake.

\section{SUMMARY}

I. Experiments were carried out to determine to what extent the impaired growth of guinea-pigs with a suboptimal intake of ascorbic acid is related to reduced food intake. The growth and food intakes of guinea-pigs receiving a suboptimal intake of ascorbic acid $(0.4 \mathrm{mg}$ daily) were compared over a period of 8 weeks with those of guinea-pigs receiving a high intake of the vitamin ( $8 \mathrm{mg}$ daily).

2. Guinea-pigs receiving suboptimal doses of ascorbic acid had a much lower rate of weight gain than pair-fed animals receiving high daily intakes of the vitamin.

3. Guinea-pigs receiving suboptimal doses of ascorbic acid showed no reduction in food intake when compared with a similar group receiving large amounts of the vitamin.

4. It is concluded that the primary effect of ascorbic acid on growth of guinea-pigs receiving the commercial pellet diet described is a metabolic one on tissue formation rather than an appetite effect resulting in changed food intake.

We are grateful to $\mathrm{Mr} \mathrm{G}$. Booth for his care of the animals used in the experiments.

\section{REFERENCES}

Albanese, A. A. (1959). In Protein and Amino Acid Nutrition, pp. 34r, 465. [A. A. Albanese, editor.] New York: Academic Press Inc.

Beaton, G. H., Hellebust, D. M., Paul, W. \& Wright, A. M. (1960). F. Nutr. 70, 32 I.

Bessey, O. A. (1938). $\mathscr{7}$. biol. Chem. r26, 77 I.

Fidanza, A. \& Constable, B. J. (1960). Quad. Nutr. 20, r.

Hughes, R. E. (1956). Biochem. F. 64, 203.

Hugot, D. \& Causerot, J. (1957). C.R. Acad. Sci., Paris, 245, 1340.

Osborne, T. B. \& Mendel, L. B. (1918). F. biol. Chem. 35, I9.

Reid, M. E. \& Briggs, G. M. (I953). F. Nutr. 5I, 341.

Stewart, J. (1953). Brit. F. Nutr. 7, 23 I. 